\title{
Serum Vitamin B12 and Homocysteine Levels in Type 2 Diabetic Patients with and without Metformin Therapy
}

\author{
Fathy Elsayed Abdelgawad ${ }^{1,2}$ (D), Gihan Mohamed Mohamed Bakri ${ }^{3}$ \\ ${ }^{1}$ Medical Biochemistry Department, Faculty of Medicine, Al-Azhar University, Cairo, Egypt; ${ }^{2}$ Medical Laboratory \\ Department, University Medical Center, Islamic University of Madinah, Madinah, KSA; ${ }^{3}$ Female Section, University \\ Medical Center, Islamic University of Madinah, Madinah, KSA
}

Correspondence to: Fathy Elsayed Abdelgawad, ftelmaamly@yahoo.com

Keywords: Diabetes, Metformin, Vitamin B12, Homocysteine, Peripheral Neuropathy

Received: November 16, $2019 \quad$ Accepted: December 17, $2019 \quad$ Published: December 20, 2019

Copyright $\odot 2019$ by author(s) and Scientific Research Publishing Inc.

This work is licensed under the Creative Commons Attribution International License (CC BY 4.0).

http://creativecommons.org/licenses/by/4.0/

\section{(c) (i) Open Access}

\section{ABSTRACT}

Background: Vitamin B12 (cobalamin) is an essential micronutrient necessary for DNA methylation and plays role in lipid metabolic reactions. Metformin is the first therapeutic choice for T2DM management. Prolonged use of metformin causes vitamin B12 deficiency due to poor absorption by interfering with calcium-based vitamin B12 absorption. Vitamin B12 deficiency leads to elevated homocysteine levels. The aim of this study was to evaluate serum vitamin B12 and homocysteine levels in type 2 diabetic patients with and without metformin therapy. Methods: A cross-sectional study was conducted on two hundred and thirty diabetic patients (180 males and 50 females). Their ages ranged from (30 - 60 years) living in Saudia Arabia at Al-Madinah Al-Monawarah. Patients were selected at outpatients clinics of Islamic University Medical Center during follow up at internal medicine and endocrinology clinic. The included patients were diagnosed with type 2 diabetes mellitus according to American Diabetes Association (ADA) Criteria. The included patients were categorized into two groups according to treatment with metformin drug. Laboratory measurements included serum level of vitamin B12, serum total homocysteine, serum fasting glucose and serum folate. Blood EDTA samples were used to measure HbAlc and MCV. Neurological examinations were performed to detect presence of peripheral neuropathy using Toronto Clinical Neuropathy Score (TCSS), which is a validated and reliable scale for the diagnosis and staging of diabetic polyneuropathy. Results: There were no statistical differences between the two groups as regard (age, sex, smoking, weight, BMI, systolic blood pressure, diastolic blood pressure, fasting blood glucose, Folate and MCV). There were statistical differences between the two groups as regard (duration of diabetes, duration of metformin therapy, dose of metformin, Serum homocystein and HbA1c). The mean of vi$\operatorname{tamin} B 12(\mathrm{pg} / \mathrm{mL})$ of group $1(312.65 \pm 92.28)$ was lower than that of group $2(381.55 \pm$ 
88.04). In group 1 number of patients with normal vitamin B12 was 116 out of 150 (77.3\%) and number of patients with deficient vitamin B12 was 34 out of 150 (22.7\%). In group 2 number of patients with normal vitamin B12 was 72 out of 80 (90\%) and number of patients with deficient vitamin B12 was 8 out of 80 (10\%). Regarding neuropathy; in group 1113 patients $(75.3 \%)$ had no neuropathy, 24 patients (16\%) had mild neuropathy and 13 patients (8.7\%) had moderate neuropathy. In group 2,71 patients $(88.8 \%)$ had no neuropathy, 7 patients $(8.7 \%)$ had mild neuropathy and 2 patients $(2.5 \%)$ had moderate neuropathy. In conclusion, in our study, the prevalence of vitamin B12 deficiency was higher in metformin users than in non-metformin users. There was an association between vitamin B12 deficiency and the dose and duration of metformin use. There was also an increase in homocysteine level due to vitamin B12 deficiency. Therefore, we recommend routine screening for serum vitamin B12 and homocysteine in individuals with T2DM who take daily metformin doses higher than $2000 \mathrm{mg}$, or for a duration exceeding 4 years.

\section{INTRODUCTION}

Vitamin B12 (cobalamin) is an essential micronutrient necessary for DNA methylation and plays role in lipid metabolic reactions. Cobalamin deficiency has been suggested as a cause of endothelial dysfunction $[1,2]$.

Type 2 diabetes mellitus (T2DM) represents $90 \%$ of the world's diabetic population and $9 \%$ of annual global deaths with health and socioeconomic problems [3]. Peripheral neuropathy is the most common complication of T2DM followed by cardiovascular, kidney and eye complications $[4,5]$. Vitamin B12 deficiency can occur in T2DM [6].

Metformin is the first therapeutic choice for T2DM management, as recommended by the American Diabetes Association and the European Association for the Study of Diabetes. Metformin improves peripheral insulin sensitivity and risk of cardiovascular mortality [7, 8]. Moreover, metformin has beneficial effects on carbohydrate metabolism, weight loss and vascular protection [9]. Most of the side effects associated with metformin are mild, such as abdominal distress and diarrhea [10]. However, it has been reported that metformin reduces the absorption of vitamin B12 in the terminal ileum [11]. Several studies have shown that long term use of metformin leads to malabsorption of vitamin B12, with a decrease in the concentration of vitamin B12 in serum from 14\% to 30\% [12]. Prolonged use of metformin causes vitamin B12 deficiency due to poor absorption by interfering with calcium-based vitamin B12 absorption [13, 14]. Neuropathy of vitamin B12 deficiency is preventable than the same caused by hyperglycaemia [15]. Metformin induced deficiency of vitamin B12 presenting as peripheral neuropathy may be mistaken for diabetic neuropathy [16]. Vitamin B12 deficiency leads to elevated homocysteine levels [17]. Homocysteine (Hcy) is a risk factor strongly associated with cardiovascular complications in T2DM. Hcy can be remethylated to methionine or trans-sulphurated to cystathionine. The former requires a 5-methyltetrahydrofolate as methyl donor and vitamin B12 as a cofactor [18]. Low vitamin B12 and hyperhomocysteinaemia with normal folate status are common among vegetarian patients [19]. Complications of T2DM are better reduced by controlling risk factors than the blood sugar [20]. Treatment with vitamin B12 without folic acid, effectively reduces Hcy in the general population, but little data in diabetics [19]. Homocysteine, which is a metabolite of vitamin B12, is used to diagnose vitamin B12 deficiency at earlier stage [21, 22].

The aim of this study was to evaluate serum vitamin B12 and homocysteine levels in type 2 diabetic patients with and without metformin therapy.

\section{SUBJECTS AND METHODS}

\subsection{Patients}

A cross-sectional study was conducted on two hundred and thirty diabetic patients (180 males and 50 
females) on the period between December 2018 to October 2019. Their ages ranged from 30 - 60 years living in Saudia Arabia at Al-Madinah Al-Monawarah. Patients were selected at outpatients clinics of Islamic University Medical Center during follow up at internal medicine and endocrinology clinic. The included patients were diagnosed with type 2 diabetes mellitus according to American Diabetes Association (ADA) Criteria $[\mathrm{HbAlC} \geq 6.5 \%$, FPG $\geq 126 \mathrm{mg} / \mathrm{dl}$, 2 -h plasma glucose $\geq 200 \mathrm{mg} / \mathrm{dl}$, In a patient with classic symptoms of hyperglycemia, a random plasma glucose $\geq 200 \mathrm{mg} / \mathrm{dl}$ ] [23].

The included patients were categorized into two groups according to treatment with metformin drug.

Group 1: Included 150 (120 males and 30 females) type 2 diabetic patients treated with metformin in a dose of $1500-2250 \mathrm{mg}$ /day in two divided doses.

Group 2: Included 80 (60 males and 20 females) type 2 diabetic patients treated with oral anti-diabetic drugs other than metformin [sulphonylurea and/or dipeptide peptidase 4 inhibitors]. The two groups matched for age and sex.

Exclusion criteria of the studied patients included the following:

1) Patients known to be vitamin B12 deficient or receiving any form of vitamin B12 supplementation during the past 6 weeks.

2) History of gastrectomy, alcoholism, ongoing pregnancy, liver disease, renal disease, thyroid disorders and history suggestive of malabsorption disorders.

3) Patients on proton pump inhibitors.

4) Vegetarians and type1diabetes mellitus patients

5) Subjects were also excluded if they had any neurologic condition like Multiple Sclerosis and blood transfusions during the last 3 months.

\subsection{All Studied Patients Were Subjected to Physical, Anthropometric, and Laboratory Examinations}

Physical examination, anthropometric measures and neurological examinations were performed in the clinic of internal medicine and endocrinology. Neurological examinations were performed to detect presence of peripheral neuropathy using Toronto Clinical Neuropathy Score (TCSS), which is a validated and reliable scale for the diagnosis and staging of diabetic polyneuropathy. TCSS was assessed by presence or absence of general symptoms, including foot pain, numbness, tingling, weakness, ataxia, and upper limb symptoms. Based on TCSS score, patients were graded into four classes: no neuropathy, 0 - 5; mild neuropathy, 6 - 8; moderate neuropathy, 9 - 11; and severe neuropathy $\geq 12$. In addition to the TCSS for neuropathy, the patients underwent a sensory examination that included pinprick, temperature, light touch, vibration and position sense [24].

\subsection{Laboratory Measurements}

After 8 - 10 hours overnight fast, blood samples were obtained from the ante cubital vein by the use of serum separator and EDTA tubes and the serum was separated by centrifugation. Laboratory measurements included serum level of vitamin B12, serum total homocysteine, serum fasting glucose and serum folate. Blood EDTA samples were used to measure HbAlc and MCV. Glucose measurements were determined following routine biochemical laboratory protocols using automated Siemens Dimension (RxL Max) clinical chemistry system. The architect B12 assay is a chemiluminescent microparticle intrinsic factor assay for the quantitative determination of vitamin B12 in human serum on the architect i system [25]. On the basis of results of vitamin B12 levels, patients were classified into normal vitamin B12 level ( $>220$ $\mathrm{pg} / \mathrm{ml})$, possible vitamin B12 deficiency $(150-220 \mathrm{pg} / \mathrm{ml})$, and definite vitamin B12 deficiency $(<150$ $\mathrm{pg} / \mathrm{ml}$ ) [26]. The architect homocysteine assay is a chemiluminescent microparticle immunoassay for the quantitative determination of total L-homocysteine in human serum on the architect i system (Normal serum homocysteine $(5.08-20.50 \mu \mathrm{mol} / \mathrm{L})$ [27]. HbAlc was determined using Siemens DCA analyzer for quantitative assay for HbAlc in blood. Both the concentrations of HbAlc specifically and the concentration of total hemoglobin were measured, and the ratio reported as percent HbAlc. All of the reagents for 
performing both reactions were contained in the DCA HbAlc cartridge [28]. The architect folate assay is a chemiluminescent microparticle folate binding protein assay for the quantitative determination of folate in human serum on the architect i system [29]. MCV was determined using cell dyne ruby hematology analyzer manufacturer Abbott.

Statistical analyses: Statistical analysis was performed using Statistical Package for Social Sciences SPSS version 25 (SPSS Inc., Chicago, IL, USA). Descriptive characteristics for participants were expressed as mean, standard deviation, number and percent for categorical data. Comparisons of anthropometric and biochemical characteristics were made using Independent $t$ test between group 1 and group 2. Pearson's correlation coefficient was used to find correlation between vitamin B12 and other quantitative parameters and linear regression analyses were carried out to find the most significant factors affect serum vitamin B12 levels.

\section{RESULTS}

The clinical and biochemical characteristics of the studied population categorized according to the treatment with metformin are presented in Table 1 . No statistical differences in the age between two groups $(48.22 \pm 6.86$ vs $48.15 \pm 6.79$ years, $\mathrm{P}=0.94)$. No statistical differences in sex between the two groups $(\mathrm{P}=0.38)$. No statistical differences in smoking between the two groups $(\mathrm{P}=0.42)$. No statistical differences in the weight between the two groups $(88.00 \pm 3.59$ vs $86.64 \pm 1.52, \mathrm{P}=0.08)$. No statistical differences in BMI between the two groups $(31.884 \pm 1.53$ vs $31.96 \pm 1.52, \mathrm{P}=0.37)$. No statistical differences in systolic blood pressure between the two groups (134.85 \pm 5.86 vs $135.58 \pm 5.62, \mathrm{P}=0.37)$. No statistical differences in diastolic blood pressure between the two groups $(89.32 \pm 2.76$ vs $90.09 \pm 3.08, \mathrm{P}=$ $0.06)$. No statistical differences in fasting blood glucose between the two groups (144.02 \pm 7.85 vs $146.98 \pm$ $5.65, \mathrm{P}=0.39)$. There are statistical differences in duration of diabetes between the two groups $(8.47 \pm 0.87$ vs $7.6 \pm 1.40, \mathrm{P}=0.001$ ). Duration of metformin therapy (ys) in group 1 was $8.05 \pm 1.50$. Number of patients treated with metformin for less than 4 ys was 10 (6.7\%) and more than 4 ys was 140 (93.3\%). Dose of metformin $(\mathrm{mg} /$ day) was $1703.33 \pm 261.3$. The mean of $\mathrm{HbA1c}(\mathrm{g} / \mathrm{dl})$ of group 1 was $8.55 \pm 0.64$ comparable with that of group $2(8.01 \pm 0.67)$. There are statistical differences in the mean of HbAlc between the two groups $(\mathrm{P}=0.001)$. No statistical differences in the red cell MCV between the two groups $(87.90 \pm$ 3.98 vs $88.23 \pm 4.10, \mathrm{P}=0.56)$. No statistical differences in the mean of serum folate between the two groups $(15.02 \pm 2.51$ vs $15.10 \pm 2.23, \mathrm{P}=0.29)$. There are statistical differences in the mean of serum homocystein $\mu \mathrm{mol} / \mathrm{L}$ of group $1(14.45 \pm 3.71)$ with that of group $2(9.84 \pm 3.42, \mathrm{P}<0.001)$ (Table 1 and Figure 1). The mean of Vitamin B12 (pg/mL) of group 1 was $312.65 \pm 92.28$ lower than that of group 2 $(381.55 \pm 88.04)$. There are highly significant differences between the two groups $(\mathrm{P}<0.001)$. In group 1 number of patients with normal vitamin B12 was 116 out of $150(77.3 \%)$ and number of patients with deficient vitamin B12 was 34 out of 150 (22.7\%) (Table 1 and Figure 2). In group 2 number of patients with normal vitamin B12 was 72 out of 80 (90\%) and number of patients with deficient vitamin B12 was 8 out of 80 (10\%) (Table 1 and Figure 2). Regarding neuropathy; in group 1113 patients (75.3\%) had no neuropathy, 24 patients $(16 \%)$ had mild neuropathy and 13 patients $(8.7 \%)$ had moderate neuropathy (Table 1 and Figure 3). In group 2, 71 patients $(88.8 \%)$ had no neuropathy, 7 patients $(8.7 \%)$ had mild neuropathy and 2 patients (2.5\%) had moderate neuropathy (Table 1 and Figure 3$)$. There is statistical differences between the two groups in neuropathy $(\mathrm{P}=0.04)$.

\section{DISCUSSION}

The incidence of type 2 diabetes is increasing all over the world, more so in the Saudi Arabia. One standard first line treatment for diabetes is metformin. There is a relationship between metformin therapy and reduction of vitamin B12 status [30].

Various hypotheses have been proposed which include an alteration in bowel motility, bacterial overgrowth and a possible direct inhibitory effect on vitamin B12 absorption [31]. 
Table 1. Clinical and biochemical parameters data of patients with type 2 diabetes mellitus in both groups.

\begin{tabular}{|c|c|c|c|}
\hline Variable & $\begin{array}{c}\text { Group I } \\
\text { Diabetes with } \\
\text { metformin } \\
(n=150) \\
\text { Mean (SD) or } n(\%)\end{array}$ & $\begin{array}{c}\text { Group II } \\
\text { Diabetes } \\
\text { with OAD other than } \\
\text { metformin }(n=80) \\
\text { Mean }(\mathrm{SD}) \text { or } \mathrm{n}(\%)\end{array}$ & $\mathbf{P}$ \\
\hline Age (years) & $48.22 \pm 6.86$ & $48.15 \pm 6.79$ & $0.94 \mathrm{NS}^{!}$ \\
\hline $\begin{array}{c}\text { Sex: } \\
\text { Male } \\
\text { Female }\end{array}$ & $\begin{array}{l}120(80 \%) \\
30(20 \%)\end{array}$ & $\begin{array}{l}60(75 \%) \\
20(25 \%)\end{array}$ & $0.38 \mathrm{NS}^{\#}$ \\
\hline Smoking & $12(8 \%)$ & $9(11.25 \%)$ & $0.42 \mathrm{NS}^{\#}$ \\
\hline Weight (kg) & $88.00 \pm 3.59$ & $86.64 \pm 3.89$ & $0.08 \mathrm{NS}^{!}$ \\
\hline $\mathrm{BMI}\left(\mathrm{kg} / \mathrm{m}^{2}\right)$ & $31.884 \pm 1.53$ & $31.96 \pm 1.52$ & $0.37 \mathrm{NS} !$ \\
\hline Systolic Blood Pressure (mmHg) & $134.853 \pm 5.86$ & $135.58 \pm 5.62$ & $0.37 \mathrm{NS} !$ \\
\hline Diastolic Blood Pressure (mmHg) & $89.32 \pm 2.76$ & $90.09 \pm 3.08$ & $0.06 \mathrm{NS}^{!}$ \\
\hline Fasting Blood Glucose (mg/dl) & $144.02 \pm 7.85$ & $145.00 \pm 5.99$ & $0.39 \mathrm{NS}^{!}$ \\
\hline Duration of diabetes (ys) & $8.47 \pm 0.87$ & $7.60 \pm 1.40$ & $<0.001^{* * !}$ \\
\hline Duration of metformin therapy (ys) & $8.05 \pm 1.50$ & & \\
\hline $\begin{array}{l}<4 \\
>4\end{array}$ & $\begin{array}{c}10(6.7 \%) \\
140(93.3 \%)\end{array}$ & - & - \\
\hline Dose of metformin mg/day & $1703.33 \pm 261.30$ & - & - \\
\hline HbAlc (\%) & $8.55 \pm 0.64$ & $8.01 \pm 0.67$ & $<0.001^{* * !}$ \\
\hline Red cell MCV (76 - 95) fL & $87.90 \pm 3.98$ & $88.23 \pm 4.10$ & $0.56 \mathrm{NS}^{!}$ \\
\hline Serum Folate $(3.1-20.5) \mathrm{ng} / \mathrm{ml}$ & $15.02 \pm 2.51$ & $15.10 \pm 2.23$ & $0.29 \mathrm{NS}^{!}$ \\
\hline Homocystein $(5.08$ - 15.39) $\mu \mathrm{mol} / \mathrm{L}$ & $14.45 \pm 3.71$ & $9.84 \pm 3.42$ & $<0.001^{* * !}$ \\
\hline Toronto clinical scoring system & $3.55 \pm 2.56$ & $2.73 \pm 2.01$ & $0.01^{* \$}$ \\
\hline \multicolumn{4}{|l|}{ Neuropathy: } \\
\hline No Neuropathy & $113(75.3 \%)$ & $71(88.8 \%)$ & \multirow{3}{*}{$0.04^{* \#}$} \\
\hline Mild Neuropathy & $24(16 \%)$ & $7(8.7 \%)$ & \\
\hline Moderate Neuropathy & $13(8.7 \%)$ & $2(2.5 \%)$ & \\
\hline Vitamin B12 (pg/Ml) & $312.65 \pm 92.28$ & $381.55 \pm 88.04$ & $<0.001^{* * !}$ \\
\hline $\begin{array}{l}\text { Normal vitamin B12 } \\
\text { Deficient vitamin B12 }\end{array}$ & $\begin{array}{c}116(77.3 \%) \\
34(22.7 \%)\end{array}$ & $\begin{array}{l}72(90 \%) \\
8(10 \%)\end{array}$ & $0.02^{* \#}$ \\
\hline
\end{tabular}

Sd: Standard deviation; 'Independent $\mathrm{t}$ test; ${ }^{\$}$ Mann Whitney test; ${ }^{*}$ Chi square test. NS: Non significant $(\mathrm{P}>$ $0.05)$; ${ }^{\star}$ Significant $(\mathrm{P}<0.05),{ }^{\star \star}$ Highly significant $(\mathrm{P}<0.01)$. 


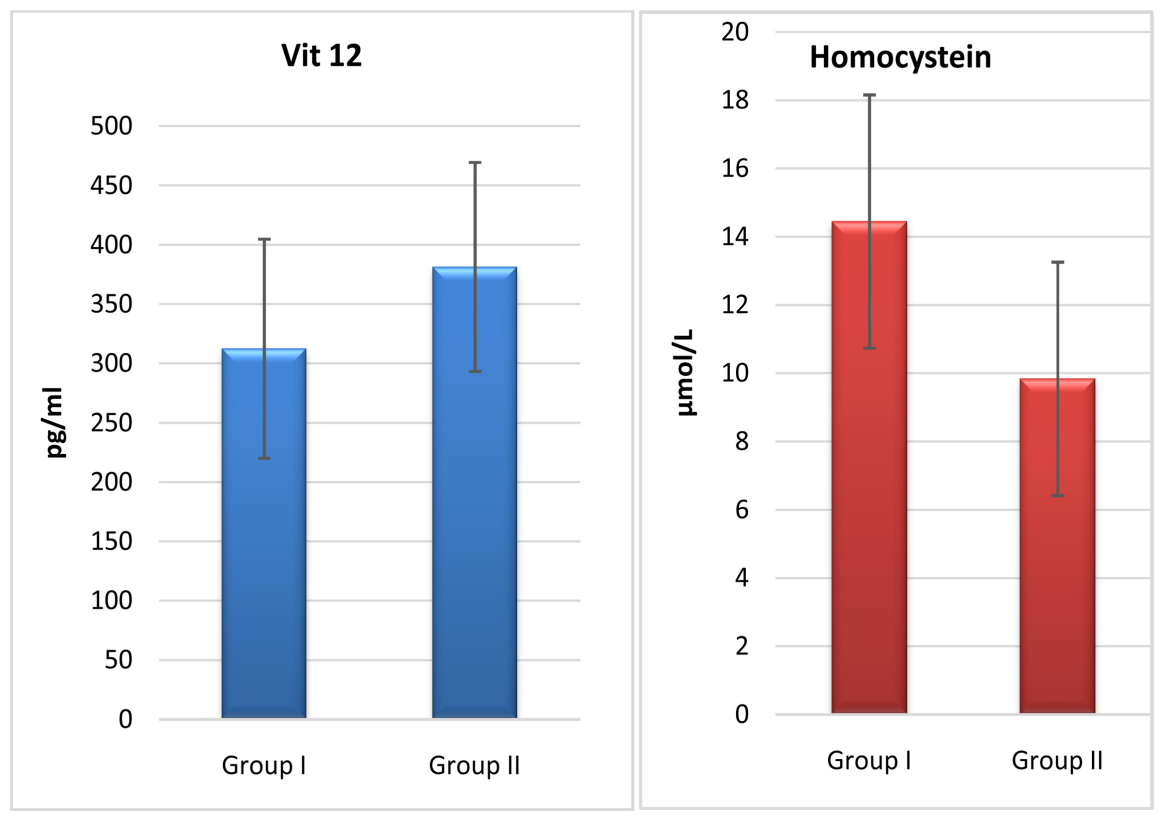

Figure 1. Diagram show mean of Vit. B12 and homocysteine in the two groups.

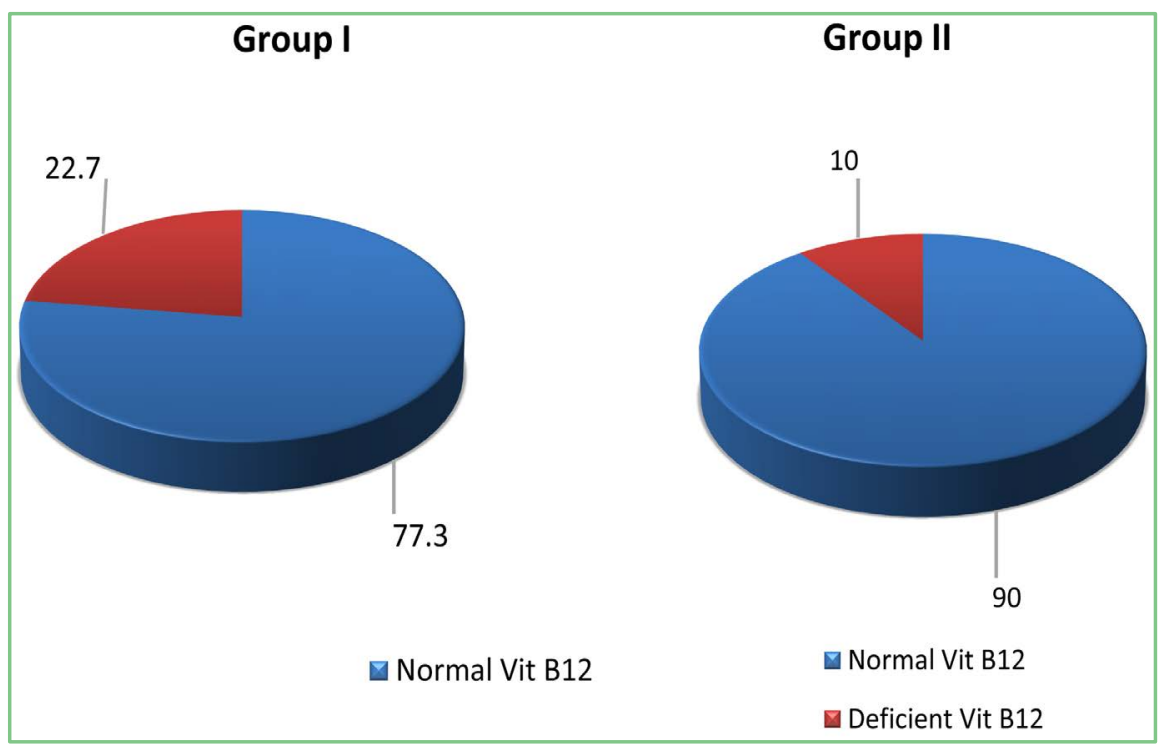

Figure 2. Diagram show normal and deficient vitamin B12 in the two groups.

Furthermore it has been suggested that metformin may affect the calcium-dependent uptake of vitamin B12-intrinsic factor complex by ileocytes; a hypothesis supported by the discovery that calcium supplements reverse the decline in vitamin B12 concentrations in these patients [32] [33].

In our study, $22.7 \%$ of T2DM patients on metformin therapy were found to have vitamin B12 deficiency and 10\% of T2DM without metformin had vitamin B12 deficiency. The deficiency is more on group of patients taking metformin; there are significantly differences $(\mathrm{P}<0.001)$. Low levels of serum vitamin B12 occurred when metformin was taken at a dose greater than $2000 \mathrm{mg} /$ day and for a period exceeding 4 years. There was negative correlation between vitamin B12 and duration and dose of metformin use $(\mathrm{r}=$ 


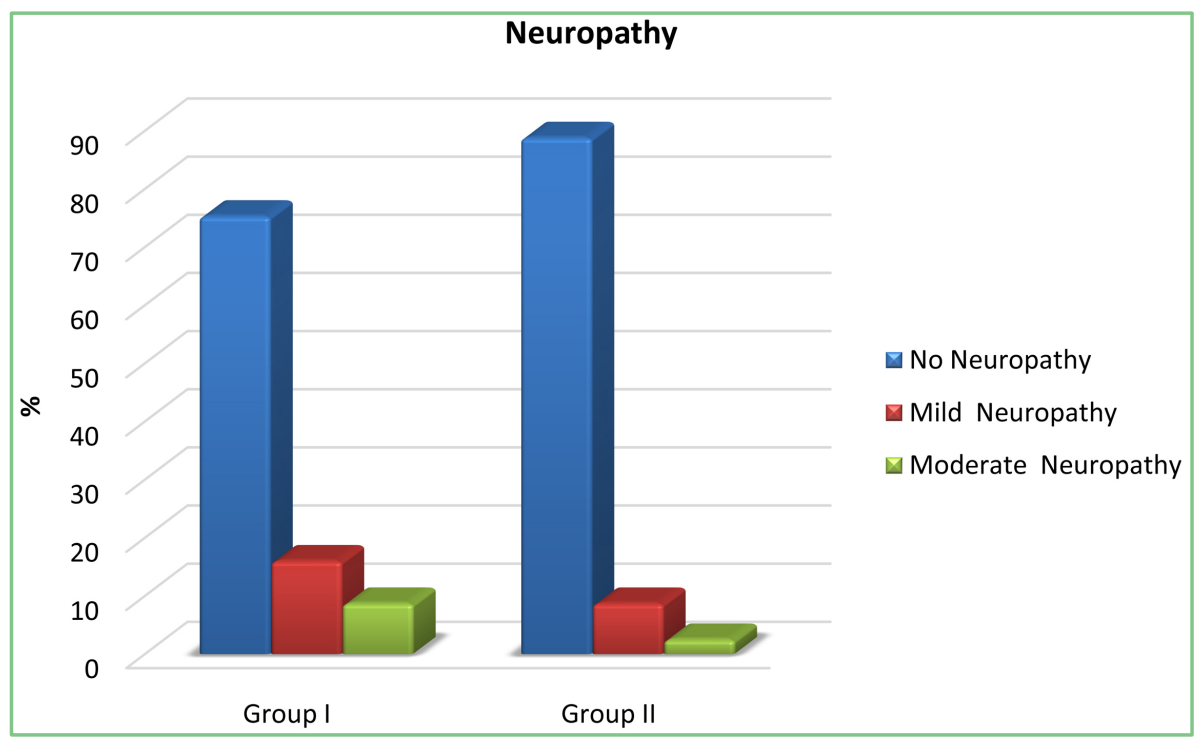

Figure 3. Prevalence of neuropathy in the two groups, based on the Toronto clinical scoring system.

$-0.290, \mathrm{P}=0.032 ; \mathrm{r}=-0.380, \mathrm{P}=0.012$ ) respectively (Table 2). Our observation of a correlation of vitamin B12 deficiency with metformin use is consistent with the results of several studies such as Obeid, et al., [34] who stated that metformin treatment was associated with low serum vitamin B12 and Reinstatler, et al., [35] who said that metformin therapy is associated with a higher prevalence of biochemical vitamin B12 deficiency.

Other study by PFlipsen et al. [36] concluded that twenty-two percent of diabetic patients had metabolically confirmed vitamin B12 deficiency. Patients taking metformin use had lower serum vitamin B12 levels and were at increased risk for vitamin B12 deficiency. The prevalence of vitamin B12 deficiency was in the range of $15 \%-30 \%$.

Also, Chapman, in a systematic review, noted that the findings of 17 cross-sectional studies showed that there was a relationship between lower levels of vitamin B12 and metformin use [37]. Another study concluded that use of metformin in T2DM is associated with vitamin B12 deficiency and worsening clinical neuropathy, which is a dose-dependent effect. Thus, they suggested screening of vitamin B12 levels in long term metformin users and treating them if they are deficient [38]. Although most studies link vitamin B12 deficiency to prolonged use of metformin, a randomized study involving 400 patients with T2DM showed that in just 16 weeks of metformin use, serum folate and vitamin B12 levels were reduced in 7\% and $14 \%$, respectively, and a $4 \%$ increase in average homocysteine levels in the blood [39].

However, other studies provided incompatible results; these studies have shown that metformin may improve the metabolism of vitamin B12 and reduce only the inactive form of vitamin B12 (holohaptocorrin) rather than the active form of vitamin B12 (holotranscobalamin) [40] [41]. In another study, serum vitamin B12 levels were not associated with metformin dose, but were associated with duration of treatment [42]. In a case-control study of 155 diabetic patients with vitamin B12 deficiency, both appeared as independent risk factors for vitamin B12 deficiency. This difference can be explained at least in part by the self-determination method used in this study to determine the dose and duration of metformin use. Metformin has adverse effects such as diarrhea, nausea and altered taste, which may lead to irregular use being reported [43].

In our study, the effect of vitamin B12 deficiency on hematological parameters such as MCV was studied. We did not find any increase or decrease in $\mathrm{MCV}$ in patients with vitamin $\mathrm{B} 12$ deficiency $(\mathrm{P}=0.56)$. Serum folate is normal in both groups $(15.02 \pm 2.51$ vs $15.10 \pm 2.23, \mathrm{P}=0.29)$ and this may be the reason for the lack of anemia associated with vitamin B12 deficiency in the studied patients. 
Table 2. Correlation of Vit. B12 and someclinical and biochemical parameters.

\begin{tabular}{|c|c|c|}
\hline & & Vitamin B12 \\
\hline \multirow{2}{*}{ Age } & $\mathrm{r}$ & 0.088 \\
\hline & $\mathrm{P}$ & $0.181 \mathrm{NS}$ \\
\hline \multirow{2}{*}{ Weight } & $\mathrm{r}$ & -0.001 \\
\hline & $\mathrm{P}$ & $0.994 \mathrm{NS}$ \\
\hline \multirow{2}{*}{ BMI } & $\mathrm{r}$ & 0.092 \\
\hline & $\mathrm{P}$ & $0.165 \mathrm{NS}$ \\
\hline \multirow{2}{*}{ SBP } & $\mathrm{r}$ & 0.006 \\
\hline & $\mathrm{P}$ & $0.931 \mathrm{NS}$ \\
\hline \multirow{2}{*}{ DBP } & $\mathrm{r}$ & 0.07 \\
\hline & $\mathrm{P}$ & $0.920 \mathrm{NS}$ \\
\hline \multirow{2}{*}{ FBG } & $\mathrm{r}$ & -0.36 \\
\hline & $\mathrm{P}$ & $0.03^{*}$ \\
\hline \multirow{2}{*}{ Duration of DM } & $\mathrm{r}$ & -0.41 \\
\hline & $\mathrm{P}$ & $0.007^{* *}$ \\
\hline \multirow{2}{*}{ Duration of mit } & $\mathrm{r}$ & -0.37 \\
\hline & $\mathrm{P}$ & $0.02^{*}$ \\
\hline \multirow{2}{*}{ Dose of Mit } & $\mathrm{r}$ & -0.39 \\
\hline & $\mathrm{P}$ & $0.01^{*}$ \\
\hline \multirow{2}{*}{$\mathrm{HbAlc}$} & $\mathrm{r}$ & -0.32 \\
\hline & $\mathrm{P}$ & $0.04^{*}$ \\
\hline \multirow{2}{*}{ Red MCV } & $\mathrm{r}$ & -0.010 \\
\hline & $\mathrm{P}$ & $0.877 \mathrm{NS}$ \\
\hline \multirow{2}{*}{ Folate } & $\mathrm{r}$ & 0.003 \\
\hline & $\mathrm{P}$ & $0.963 \mathrm{NS}$ \\
\hline \multirow{2}{*}{ Homocystein } & $\mathrm{r}$ & -0.612 \\
\hline & $\mathrm{P}$ & $<0.001^{\star *}$ \\
\hline
\end{tabular}

r: Correlation coefficient; NS: Non significant $(\mathrm{P}>0.05) ;{ }^{\star}$ Significant $(\mathrm{P}<0.05) ;{ }^{\star \star}$ Highly significant $(\mathrm{P}$ $<0.01)$.

Nishant Raizada et al. [44], In examining the effect of vitamin B12 deficiency on hematological parameters such as MCV and hemoglobin did not find any increase in MCV or decrease in hemoglobin in vitamin B12 deficient patients. In their study, the metformin use was associated with significantly lower serum vitamin B12 levels when adjusted for duration of diabetes. Patients with vitamin B12 deficiency did not have a high incidence of anemia. Another study, reported anemia in $23.3 \%$ of patients using metformin compared with $22.3 \%$ in patients not using metformin [45].

In our study, there was negative correlation between HbA1c and vitamin B12 deficiency ( $\mathrm{r}$ : $-0.34, \mathrm{P}$ : 0.043), but in multivariate Analysis no significant correlation between Vitamin B12 and HbA1c (Table 3). In another study the relationship between fasting blood glucose and HbAlc was analyzed with the markers of vitamin B12 and no relationship existed between them [46]. Another study by Anand et al., reported that although, many patients had good control of $\mathrm{HbAlc}$, but the HbAlc was slightly higher in the deficiency group when compared to the normal group [47].

Our study demonstrated that individuals with vitamin B12 deficiency had a significantly higher level 
Table 3. Multivariate analysis of significant correlated variables with vitamin B12 in the studied groups.

\begin{tabular}{cccc}
\hline Variables & Regression Coefficient & SE & P \\
\hline FBS (mg/dl) & 0.003 & 0.001 & $0.98 \mathrm{NS}$ \\
Duration of DM (years) & 0.520 & 1.85 & $0.02^{\star}$ \\
Duration of metformin (years) & 0.49 & 1.71 & $0.03^{\star}$ \\
Dose of mitformin & 0.550 & 1.98 & $0.01^{\star}$ \\
HbAlc $\%$ & 0.245 & 0.073 & $0.13 \mathrm{NS}$ \\
Homocystein & 0.71 & 2.05 & $<0.001^{\star *}$ \\
\hline
\end{tabular}

$\mathrm{r}=0.81, \mathrm{r}^{2}=0.65$, ANOVA $\mathrm{P}<0.001^{\star *} ;$ Durbin-Watson ratio $=2.07$; Predicted value $=312$.

of serum homocysteine than individuals with normal serum vitamin B12. There was negative correlation between vitamin $\mathrm{B} 12$ and homocysteine $(\mathrm{r}=-0.612, \mathrm{P}<0.001)$ (Table 2). A similar finding has been reported by Wulffelé et al., [39] who stated that treatment of type 2 diabetic patients with metformin reduces levels of folate and vitamin B12, leading to a modest increase in homocysteine. Asimilar finding was also reported by Ananda, et al., which stated that the total homocysteine concentration in serum and plasma is elevated in both folate and cobalamin deficiencies, and hyperhomocysteinemia is associated with an increased risk of cardiovascular disease, cognitive dysfunction, and adverse pregnancy outcomes [48]. Twinkal et al., concluded that strong inverse association between serum vitamin B12 and serum Hcy was found in all the studied Patients on metformin [49].

Another study was performed by the Yuka Sato et al., [50] who found that serum vitamin B12 decreased in patients with diabetes, even in the absence of metformin use, and further decreased by metformin in a dose-dependent manner. This is a direct effect of the drug. Hcy is increased in relation to the reduction of vitamin B12 caused by metformin. Thus, metformin directly lowers serum vitamin B12 while the drug is indirectly raising plasma Hcy via the lowering of vitamin B12. However, some studies have reported that metformin therapy has no effect, or only a small effect, on homocysteine concentration [51]. Another study indicated that the administration of metformin could induce vitamin B12 deficiency in patients with type 2 diabetes but plasma Hcy levels did not show a significant difference between those in the metformin and the non-metformin groups [52] [53].

The neurologic manifestations begin pathologically with demyelination, followed by axonal degeneration and axonal death that can cause eventual irreversible damage. The spinal cord, brain, optic nerves, and peripheral nerves may all be affected by cobalamin deficiency [54]. Wile and Toth [55] found that beside low cobalamin level, metformin treated patients also had an elevated level of homocysteine and methylmalonic acid. They also identified the deterioration of peripheral neuropathy in those patients. Neurological findings of cobalamin deficiency are often misdiagnosed with diabetic peripheral neuropathy, but at some point they can be determined, for example by assessing the presence of reflexes. Reflexes are usually preserved in the case of cobalamin deficiency, but are almost lost in the case of diabetic neuropathy [56].

Our results found that a higher incidence of peripheral neuropathy in metformin users than non metformin users, mild ( $16 \%$ vs $8.7 \%$ ) respectively and moderate ( $8.7 \%$ vs $2.5 \%)$ respectively, these results similar to a result reported by Kamphuis et al. [57], and Hendrawati et al. [58] and Alpesh Chauhan et al. [59].

However, it was not in harmony with other studies done by Tarik Elhadd et al., that show no difference in vitamin B12 levels between metformin and non-metformin users and no difference in the prevalence of diabetic neuropathy in T2DM patients with and without vitamin B12 deficiency [60].

In conclusion, in our study, the prevalence of vitamin B12 deficiency was higher in metformin users than in nonmetformin users. There was also an association between vitamin B12 deficiency and the dose 
and duration of metformin use. There was also an increase in homocysteine level due to vitamin B12 deficiency. Therefore, we recommend routine screening for serum vitamin B12 and homocysteine in individuals with T2DM who take daily metformin doses higher than $2000 \mathrm{mg}$, or for a duration exceeding 4 years. Early discovery of cobalamin deficiency and hyperhomocysteinemia permits physicians to employ many approaches in order to prevent deterioration of clinical manifestations and improve patients' health for good life.

\section{ACKNOWLEDGEMENTS}

I extend my sincere thanks to the Deanship of Scientific Research at the Islamic University of Madinah for helping me and providing financial support in order to do this research. Also; many thanks to $\mathrm{dr}$ Fayez Elkenawy consultant of endocrinology in the department of internal medicine at the university medical center for helping me in the clinical examination of patients participating in this research. Also many thanks go to all of my colleagues in the laboratory department of the University Medical Center for helping and encouraging me to carry out this research.

\section{CONFLICTS OF INTEREST}

The author declares no conflicts of interest regarding the publication of this paper.

\section{REFERENCES}

1. Adaikal Akoteswari, A., Jayashri, R., Sukumar, N., Venkataraman, H., Prdeepa, R. and Gokulakrishan, K. (2014) Vitamin B 12 Deficiency Is Associated with Adverse Lipid Profile in Europeans and Indians with Type 2 Diabetes. Cardiovascular Diabetology, 13, 129. https://doi.org/10.1186/s12933-014-0129-4

2. McNulty, H., Pentieva, K., Hoey, L. and Ward, M. (2008) Homocysteine, B-Vitamins and CVD. Proceedings of the Nutrition Society, 67, 232-237. https://doi.org/10.1017/S0029665108007076

3. Patel, M., Patel, I., Patel, Y. and Rathi, S. (2011) A Hospital-Based Observational Study of Type 2 Diabetic Subjects from Gujarat, India. Journal of Health, Population and Nutrition, 29, 265-272. https://doi.org/10.3329/jhpn.v29i3.7874

4. Mohan, V., Shah, S. and Saboo, B. (2013) Current Glycemic Status and Diabetes Related Complications among Type 2 Diabetes Patients in India: Data from the Alchieve Study. The Journal of the Association of Physicians of India, 61, 12-15.

5. Chen, S., Lansdown, A., Moat, S., Ellis, R., Goringe, A. and Dunstan, F. (2012) An Observational Study of the Effect of Metformin on B12 Status and Peripheral Neuropathy. The British Journal of Diabetes \& Vascular Disease, 12, 189-193. https://doi.org/10.1177/1474651412454924

6. Satyanarayana, A., Balakrishna, N., Pitla, S., Reddy, P., Mudili, S. and Lopamudra, P. (2011) Status of B-Vitamins and Homocysteine in Diabetic Retinopathy: Association with Vitamin-B12 Deficiency and Hyperhomocysteinaemia. PLoS ONE, 6, e26747. https://doi.org/10.1371/journal.pone.0026747

7. Zinman, B., Gerich, J., Buse, J., Lewin, A., Schwartz, S. and Raskin, P. (2010) American Diabetes Association. Standards of Medical Care in Diabetes. Diabetes Care, 33, 692.

8. Mazokopakis, E. and Starakis, I. (2012) Recommendations for Diagnosis and Management of Metformin-Induced Vitamin B12 Deficiency. Diabetes Research and Clinical Practice, 97, 359-367. https://doi.org/10.1016/j.diabres.2012.06.001

9. Group UPDS (1998) Effect of Intensive Blood-Glucose Control Withmetformin on Complications in Overweight Patients with Type 2 Diabetes (UKPDS 34). The Lancet, 352, 854-865. https://doi.org/10.1016/S0140-6736(98)07037-8

10. Nathan, D., Buse, J., Davidson, M., Heine, R., Holman, R. and Sherwin, R. (2006) Management of Hypergly- 
caemia in Type 2 Diabetes: A Consensus Algorithm for the Initiation and Adjustment of Therapy. Diabetologia, 49, 1711-1721. https://doi.org/10.1007/s00125-006-0316-2

11. Akinlade, K.S., Agbebaku, S.O., Rahamon, S.K. and Balogun, W.O. (2015) Vitamin B12 Levels in Patients with Type 2 Diabetes Mellitus on Metformin. Annals of Ibadan Postgraduate Medicine, 13, 79-83.

12. Ting, W., Szeto, C., Chan, M., Ma, K. and Chow, K. (2006) Risk Factors of Vitamin B12 Deficiency in Patients Receiving Metformin. Archives of Internal Medicine, 166, 1975-1979.

https://doi.org/10.1001/archinte.166.18.1975

13. Mahajan, R. and Gupta, K. (2010) Revisiting Metformin: Annual Vitamin B12 Supplementation May Become Mandatory with Long-Term Metformin Use. Journal of Young Pharmacists, 2, 428-429. https://doi.org/10.4103/0975-1483.71621

14. Nervo, M., Lubini, A., Raimundo, F., Faulhaber, G., Leite, C. and Fischer, L. (2011) Vitamin B12 in Metformin-Treated Diabetic Patients: A Cross-Sectional Study in Brazil. Revista da Associação Médica Brasileira, 57, 46-49.

15. Aisen, P. and High-Dose, B. (2008) Vitamin Supplementation and Cognitive Decline in Alzheimer Disease: A Randomized Controlled Trial. The Journal of the American Medical Association, 300, 1774-1783. https://doi.org/10.1001/jama.300.15.1774

16. Ko, S., Ahn, Y., Song, K., Han, K. and Park, Y. (2014) Association of Vitamin B12 Deficiency and Metformin Use in Patients with Type 2 Diabetes. Journal of Korean Medical Science, 29, 965-972. https://doi.org/10.3346/jkms.2014.29.7.965

17. Herrmann, W., Obeid, R., Schorr, H. and Geisel, J. (2005) The Usefulness of Holotranscobalamin in Predicting Vitamin B12 Status in Different Clinical Settings. Current Drug Metabolism, 6, 47-53. https://doi.org/10.2174/1389200052997384

18. Selhub, J. and Miller, J. (1992) The Pathogenesis of Homocysteinemia: Interruption of the Coordinate Regulation by S-Adenosylmethionine of the Remethylation and Transsulfuration of Homocysteine. The American Journal of Clinical Nutrition, 55, 131-138. https://doi.org/10.1093/ajcn/55.1.131

19. Deshmukh, U., Joglekar, C., Lubree, H., Ramdas, L., Bhat, D. and Naik, S. (2010) Effect of Physiological Doses of Oral Vitamin B12 on Plasma Homocysteine: A Randomized, Placebo-Controlled, Double-Blind Trial in India. The European Journal of Clinical Nutrition, 64, 495-502.

20. Kannel, W. (2010) Framingham Study Insights on Diabetes and Cardiovascular Disease. Clinical Chemistry, 57, 338-339. https://doi.org/10.1373/clinchem.2010.149740

21. Sahin, M. and Tutuncu, N.B. (2007) Effects of Metformin or Rosiglitazone on Serum Concentrations of Homocysteine, Folate, and Vitamin B12 in Patients with Type 2 Diabetes Mellitus. Journal of Diabetes and its Complications, 21, 118-123. https://doi.org/10.1016/j.jdiacomp.2005.10.005

22. Sobczynska-Malefora, A., Harrington, D., Voong, K. and Shearer, M. (2014) Plasma and Red Cell Reference Intervals of 5-Methyl Tetra Hydro Folate of Healthy Adults in Whom Biochemical Functional Deficiencies of Folate and Vitamin B 12 Had Been Excluded. Advances in Hematology, 2014, Article ID: 465623. https://doi.org/10.1155/2014/465623

23. American Diabetes Association (2004) Diagnosis and Classification of Diabetes Mellitus. Diabetes Care, 27, s5-s10. https://doi.org/10.2337/diacare.27.2007.S5

24. Abraham, A., Barnett, C., Katzberg, H., Lovblom, L., Perkins, B. and Bril,V. (2018)Toronto Clinical Neuropathy Score Is Valid for a Wide Spectrum of Polyneuropathies. European Journal of Neurology, 25, 484-490. https://doi.org/10.1111/ene.13533

25. Lee, D. and Griffiths, B. (1985) Human Serum Vitamin B12 Assay Methods-A Review. Clinical Biochemistry, 


\section{8, 261-266. https://doi.org/10.1016/S0009-9120(85)80028-X}

26. Snow, C.F. (1999) Laboratory Diagnosis of Vitamin B12 and Folate Deficiency: A Guide for the Primary Care Physician. Archives of Internal Medicine, 159, 1289-1298. https://doi.org/10.1001/archinte.159.12.1289

27. Malinow, M. (1995) Plasma Homocysteine and Arterial Occlusive Diseases: A Mini-Review. Clinical Chemistry, 41, 173-176.

28. Little, R., Rohlfing, C., Wiedmeyer, H. M., Myers, G., Sacks, D. and Goldstein, D. (2001) NGSP Steering Comittee: The National Glycohemoglobin Standardization Program: A Five-Year Progress Report. Clinical Chemistry, 47, 1985-1992.

29. Steinberg, S. (1984) Mechanisms of Folate Homeostasis. American Journal of Physiology, 246, 319-324. https://doi.org/10.1152/ajpgi.1984.246.4.G319

30. Solomon, L.R. (2011) Diabetes as a Cause of Clinically Significant Functional Cobalamin Deficiency. Diabetes Care, 34, 1077-1080. https://doi.org/10.2337/dc11-0009

31. Caspary, W., Zavada, I. and Reimold, W. (1977) Alteration of Bile Acid Metabolism and Vitamin-B12-Absorption in Diabetes on Biguanides. Diabetologia, 13, 187-193. https://doi.org/10.1007/BF01219698

32. Bauman, W., Shaw, S., Jayatilleke, E., Spungen, A. and Herbert, V. (2000) Increased Intake of Calcium Reverses Vitamin B12 Malabsorption Induced by Metformin. Diabetes Care, 23, 1227-1231.

33. Gilligan, M. (2002) Metformin and Vitamin B12 Deficiency. Archives of Internal Medicine, 162, 484-490.

34. Obeid, R., Jung, J., Falk, J., Herrmann, W., Geisel, J. and Friesenhahn-Ochs, B. (2013) Serum Vitamin B12 Not Reflecting Vitamin B12 Status in Patients with Type 2 Diabetes. Biochimie, 95, 1056-1061.

https://doi.org/10.1016/j.biochi.2012.10.028

35. Reinstatler, L., Qi, Y., Williamson, R., Garn, J. and Oakley, G. (2012) Association of Biochemical B12 Deficiency with Metformin Therapy and Vitamin B12 Supplements. Diabetes Care, 35, 327-333.

https://doi.org/10.2337/dc11-1582

36. Pflipsen, M., Oh, R., Saguil, A., Seehusen, D., Seaquist, D. and Topolski, R. (2009) The Prevalence of Vitamin B(12) Deficiency in Patients with Type 2 Diabetes: A Cross Sectional Study. The Journal of the American Board of Family Medicine, 22, 528-534. https://doi.org/10.3122/jabfm.2009.05.090044 https://doi.org/10.3122/jabfm.2009.05.090044

37. Chapman, L., Darling, A. and Brown, J. (2016) Association between Metformin and Vitamin B12 Deficiency in Patients with Type 2 Diabetes: A Systematic Review and Meta-Analysis. Diabetes \& Metabolism, 42, 316-327. https://doi.org/10.1016/j.diabet.2016.03.008

38. Singh, A., Kumar, A., Karmakar, D. and Jha, R. (2013) Association of B12 Deficiency and Clinical Neuropathy with Metformin Use in Type 2 Diabetes Patients. Journal of Postgraduate Medicine, 59, 253-257. https://doi.org/10.4103/0022-3859.123143

39. Wulffele, M., Kooy, A., Lehert, P., Bets, D., Ogterop, J. and Borger, B. (2003) Effects of Short-Term Treatment with Metformin on Serum Concentrations of Homocysteine, Folate and Vitamin B12 in Type 2 Diabetes Mellitus: A Randomized, Placebo-Controlled Trial. Journal of Internal Medicine, 254, 455-463.

https://doi.org/10.1046/j.1365-2796.2003.01213.x

40. Leung, S., Mattman, A., Snyder, F., Kassam, R., Meneilly, G. and Nexo, E. (2010) Metformin Induces Reductions in Plasma Cobalamin and Haptocorrin Bound Cobalamin Levels in Elderly Diabetic Patients. Clinical Biochemistry, 43, 759-760. https://doi.org/10.1016/j.clinbiochem.2010.02.011

41. Greibe, E., Trolle, B., Bor, M., Lauszus, F. and Nexo, E. (2013) Metformin Lowers Serum Cobalamin without Changing Other Markers of Cobalamin Status: A Study on Women with Polycystic Ovary Syndrome. Nutrients, 


\section{5, 2475-2482. https://doi.org/10.3390/nu5072475}

42. Ting, R., Szeto, C., Chan, M., Ma, K. and Chow, K. (2006) Risk Factors of Vitamin B(12) Deficiency in Patients Receiving Metformin. Archives of Internal Medicine, 166, 1975-1979. https://doi.org/10.1001/archinte.166.18.1975

43. Cacy, E. (2006) Tolerability, and Safety of a Novel Once-Daily Extended Release Metformin in Patients with Type 2 Diabetes. Diabetes Care, 29, 759-764. https://doi.org/10.2337/diacare.29.04.06.dc05-1967

44. Nishant, R., Viveka, P., Jyotsna, V. and Nikhil, T. (2017) Serum Vitamin B12 Levels in Type 2 Diabetes Patients on Metformin Compared to those Never on Metformin. Indian Journal of Endocrinology and Metabolism, 21, 424-428. https://doi.org/10.4103/ijem.IJEM 52916

45. Groenier, K., Houweling, S., Bilo, H. and Kleefstra, N. (2013) Vitamin B12 Deficiency and the Lack of Its Consequences in Type 2 Diabetes Patients Using Metformin. The Netherlands Journal of Medicine, 71, 386-390.

46. Setola, E., Monti, L., Gallucio, E., Palloshi, A., Fragasso, G. and Paroni, R. (2004) Insulin Resistance and Endothelial Function Are Improved after Folate and Vitamin B12 Therapy in Patients with Metabolic Syndrome: Relationship between Homocysteine Levels and Hyperinsulinemia. European Journal of Endocrinology, 151, 483-489. https://doi.org/10.1530/eje.0.1510483

47. Anand, K., Gavisiddanagowda, P., Basavaraj, D. and Varun, B. (2017) Evaluation of Serum Vitamin B12 Levels in Type 2 Diabetes Mellitus on Metformin Therapy Attending a Tertiary Care Hospital. Journal of Evidence Based Medicine and Health Care, 4, 5399-5404. https://doi.org/10.18410/jebmh/2017/1080

48. Ananda, V., Ramesh, R., Shaik, A., Radhika, G. and Abu Raghavan, S. (2018) Evaluation of Vitamin B12 Status in Type 2 Diabetes Mellitus Patients on Metformin Therapy. Asian Journal of Medical Sciences, 9), 9-12. https://doi.org/10.3126/ajms.v9i2.18806

49. Twinkal, R., Nitin, K. and Hitesh, S. (2016) Association between Serum B12 and Serum Homocysteine Levels in Diabetic Patients on Metformin. Journal of Clinical and Diagnostic Research, 10, 1-4.

50. Yuka, S., Kenjiro, O., Yoshiko, F., Keishi, Y. and Toru, A. (2013) Relationship between Metformin Use, Vitamin B12 Deficiency, Hyperhomocysteinemia and Vascular Complications in Patients with Type 2 Diabetes. Endocrine Journal, 60, 1275-1280. https://doi.org/10.1507/endocrj.EJ13-0332

51. Hoogeveen, E., Kostense, P., Beks, P., Mackaay, A., Jakobs, C. and Bouter, L. (1998) Hyperhomocysteinemia Is Associated with an Increased Risk of Cardiovascular Disease, Especially in Non-Insulin-Dependent Diabetes Mellitus. Arteriosclerosis, Thrombosis, and Vascular Biology, 18, 133-138. https://doi.org/10.1161/01.ATV.18.1.133

52. Yilmaz, M., Bukan, N., Ayvaz, G., Karakoç, A., Törüner, F. and Cakir, N. (2005) The Effects of Rosiglitazone and Metformin on Oxidative Stress and Homocysteine Levels in Lean Patients with Polycystic Ovary Syndrome. Human Reproduction, 24, 3333-3340. https://doi.org/10.1093/humrep/dei258

53. Pongchaidecha, M., Srikusalanukul, V., Chattananon, A. and Tanjariyaporn, S. (2004) Effect of Metformin on Plasma Homocysteine, Vitamin B12 and Folic Acid: A Cross-Sectional Study in Patients with Type 2 Diabetes Mellitus. Journal of the Medical Association of Thailand, 87, 780-787.

54. Miller, A., Korem, M., Almog, R. and Galboiz, Y. (2005) Vitamin B12, Demyelination, Remyelination and Repair in Multiple Sclerosis. Journal of the Neurological Sciences, 233, 93-97.

https://doi.org/10.1016/j.jns.2005.03.009

55. Wile, D. and Toth, C. (2010) Association of Metformin, Elevated Homocysteine, and Methylmalonic Acid Levels and Clinically Worsened Diabetic Peripheral Neuropathy. Diabetes Care, 33, 156-161. https://doi.org/10.2337/dc09-0606

56. Bell, D.S. (2010). Metformin-Induced Vitamin B12 Deficiency Presenting as a Peripheral Neuropathy. Southern 
Medical Journal, 103, 265-267. https://doi.org/10.1097/SMJ.0b013e3181ce0e4d

57. de Groot-Kamphuis, D., van Dijk, P., Groenier, K., Houweling, S., Bilo, H. and Kleefstra, N. (2013) Vitamin B12 Deficiency and the Lack of Its Consequences in Type 2 Diabetes Patients Using Metformin. The Netherlands Journal of Medicine, 71, 386-390.

58. Hendrawati, Y., Andrajati, R., Supardi, S. and Ariyani, A. (2018) The Risk of Cobalamin Deficiency Symptoms Related to Long Term Metformin Use in T2DM Patients. Acta Endocrinologica, 14, 49-54. https://doi.org/10.4183/aeb.2018.49

59. Alpesh, C., Ashwini, P., Uma, B. and Shreepa, B. (2018) Screening and Assessment of Polyneuropathy in Diabetic Patients and the Effect of Vitamin B12 Administration on the Course of Neuropathy. Journal of Clinical and Diagnostic Research, 12, 10-13.

60. Tarik, E., Georgios, P., Zeinab, D., Mashhood, S., Subitha, C. and Rayaz, A. (2018) Metformin Use Is Not Associated with B12 Deficiency or Neuropathy in Patients with Type 2 Diabetes Mellitus in Qatar. Frontiers in Endocrinology, 9, 248. 